\title{
Combined in situ experimentation and modelling approaches to disentangle processes involved in the earliest stage of community assembly
}

\author{
S. Fanfard 1 , F. Charles 1 , J. Coston-Guarini², C. Nozais ${ }^{3}$ and J.-M. Guarini1 ${ }^{1,2,4}$ \\ ${ }^{1}$ Laboratoire d'Ecogéochimie des Environnements Benthiques, 66650 Banyuls/mer, France \\ ${ }^{2}$ Laboratoire des Sciences de l'Environnement Marin (LEMAR), UMR 6539, IUEM, Université de Bretagne \\ Occidentale, 29280 Plouzané, France \\ ${ }^{3}$ Université du Québec à Rimouski, Département de Biologie, 300 allée des Ursulines, Rimouski, Québec, \\ Canada G5L $3 A 1$ \\ ${ }^{4}$ Corresponding author. E-mail: jean-marc.guarini@upmc.fr, Telephone: +33 4 68887359, Fax: +33 468887395
}

Key words: Colonization, Community ecology, Experiment, Predation, Stochastic model.

\begin{abstract}
The ecological process of community assembly is described as the succession of three phases: colonization, regulation and segregation. Early colonization remains the least studied and quantified phase of assembly. In order to fill this gap, an approach combining in situ experiments and modelling was proposed to study colonization by a benthic macrofauna community in open microcosms containing a single, non-limiting resource. The experiment was three months long. A total of 51 taxa were observed in the microcosms, but data analyses of the species composition and abundances revealed that five species, Capitella spp., Gammaropsis maculata, Erichtionus punctatus, Nereiphylla paretti and Harmothoe mariannae, explained most of the observed variation in the assembly process. The population dynamics of these species were simulated taking into account functional traits that govern individual interactions. The dynamic model simulated a demographic stochasticity due to low population densities that result from the small size of the experimental microcosms. Using this combined approach of experiments and modelling, we showed that predation interactions alone can account for the abundances and species composition of primary consumers during the transient phase of early colonization.
\end{abstract}

Nomenclature: Bellan-Santini et al. $(1982,1989,1998)$ and Fauvel $(1923,1927)$.

Abbreviations: FCA-Factorial Correspondence Analysis, MCA-Multiple Correspondence Analysis.

\section{Introduction}

To identify processes involved in community assembly remains a central challenge in ecology (Weiher et al. 2011). Usually communities are observed long after they have been established, hence there has been a considerable effort made to estimate the relative influence of local or regional processes on existing species assemblages (Holyoak et al. 2005, Moritz et al. 2009, Moritz et al. 2013), rather than on describing the early colonization processes and their respective importance in the regulation of the species' assemblage.

In 1991, Drake compiled an overview of laboratory experiments on communities in which populations are placed in controlled conditions to quantify the effects of biotic or abiotic factors on community assemblages (Arroyo et al. 2006, Maria et al. 2011, Naser 2011, Fahimipour and Hein 2014). Unfortunately, the act of pre-selection of a set of populations, extracted from their natural environment and placed in different experimental conditions, influenced directly the assembly processes and biased quantification of the colonization process (Drake 1991). Since Charles Darwin cleared and observed tiny experimental plots in his lawn at Down House, many other studies have been conducted on experimental depopulated areas in the field (Eggleston et al. 1999, Lu and $\mathrm{Wu}$ 2000) or in meso-scale experimental facilities (Drake 1991, Lee 1999, Arroyo et al. 2006). However, in these approaches the initial substrate and food resources are not controlled and sometimes even altered by the depopulation process itself (Petraitis and Dudgeon 1999). Thus, to cope with these problems, experimental study of colonization should be based on natural community assembly, using controlled substrate and food sources.

Clearly, today, observations and experiments alone are not sufficient for the study of processes involved in community assembly. Modelling approaches must be developed to identify and quantify processes (Tilman 1994, 2004, Chesson 2000), but quantitative models representing the colonization stage of new substrates by ecological communities are scarce, and even fewer approaches rest on the coupled definition of experimental settings and modelling designs (Drake 1991). Furthermore, studies on early community assembly considered the colonization stage from the single perspective of competition (Leibold et al. 2004, Tilman 2004), even if, more recently, some research has started to suggest that the predation process might have a regulatory effect on the species composition of communities (Kraus and Vonesh 2010). 
Disentangling processes involved in colonization is often difficult because of the complexity of ecological interactions involved between biotic and abiotic compartments. This can be simplified by selecting ecological communities made up of few populations feeding on a single food resource. This could be achieved by using physical barriers to narrow the size range of the organisms, rather than experimentally manipulating species, and by considering natural populations that use a food source which is locally present, but not renewable during the experimental period. It has therefore been suggested that these types of experiments should target species that rely on detrital allochtonous organic matter (Moore et al. 2004).

The present study aims to identify processes which structure a new assemblage in the very early phase of colonization. We focus on marine communities of benthic macro-invertebrates (Palmer et al. 1996). Sets of microcosms, submerged in situ, held only one allochtonous organic resource, common in the coastal watershed. Changes in biological diversity (in terms of species and abundances) were inferred from the microcosm content at different intervals. Independently, a generic model of the dynamics of colonization was developed, and was used to simulate the conditions of the experimental system, based on the possible range of interactions between organisms and the resource. This model then was parameterized with the functional traits of the species identified within the microcosms. In this way, a suite of possible interactions which could structure the community assembly process were refined by comparing simulation outputs with experimental results.

\section{Material and methods}

\section{Experimental design}

Experiments were designed to induce, in situ, colonization of microcosms by small benthic macrofaunal individuals. The number of primary food resources available for benthic organisms was reduced to one, with the expectation of finding a lower diversity compared to the un-segregated system. Twelve microcosms were made of cylindrical cages of $8.5 \mathrm{~cm}$ in height and $8 \mathrm{~cm}$ in diameter, built from a plastic trellis with a $3 \mathrm{~mm}$ square mesh. A portion of allochtonous detritic organic matter resource (leaves of Vitis vinifera common in the watershed of the Bay of Banyuls-sur-Mer), was inserted in the microcosms. Each microcosm contained $10 \mathrm{~g}$ of leaves previously dried at $60{ }^{\circ} \mathrm{C}$ for 48 hours. Two primary assumptions were made: 1 . the quantity would not be a limiting factor during the experiment and, 2. the composition and structure would not change in such a way that it could modify interactions between species. The duration of the experiment was 3 months, which corresponds to the typical time for the early colonization phase of a benthic macrofaunal community reported in the literature (Drake 1991, Scrimgeour et al. 1988, McCreary Waters et al. 2005).

An experimental unit is defined as a set of 4 microcosms. Three of the four microcosms were considered as replicates and the fourth was a "control" for attesting the cumulative effect of processes different from the direct colonization and consumption of leaves by small macrofauna (leaves' degradation by bacteria, consumption by meiofauna, or recruitment of individuals arrived at the larval stage ...). This "control" was inserted in a second nylon net to exclude the arrival (or departure) of organisms larger than $200 \mu \mathrm{m}$. The four microcosms of the same unit were anchored at 1 meter from each other. Three experimental units were installed at the beginning of the experiment, spaced by about $5 \mathrm{~m}$, in the Bay of Banyuls-sur-Mer at a depth of $26 \mathrm{~m}\left(42^{\circ} 29^{\prime} 309 \mathrm{~N}, 03^{\circ} 08^{\prime} 619\right.$ E). At the study site, the surface sediments are sandy-muds. At initiation, in March 2012, the microcosms contained no organisms. One unit of four microcosms was sampled each month for 3 months (April, May and June 2012), to observe both temporal and inter-microcosm variability. In the results and discussion, these samples are referred to by sampling month number (M1, M2 or M3) and replicate numbers (E1, $\mathrm{E} 2$ or E3 for experimental microcosms, and $\mathrm{C}$ for the control).

Immediately after collection, the content of each microcosm was transferred in bags filled with $4 \%$ formaldehyde for preservation. Organisms were sorted and only individuals larger than $1 \mathrm{~mm}$ were retained. The majority were identified to the species level, counted and preserved in $70 \%$ ethanol. Sex and reproductive evidence (presence of eggs, larvae or new recruits) were recorded when observed.

\section{Data analysis}

Experimental results required a statistical analysis of the spatial (inter-microcosm) and temporal (inter-unit) variability of the observations of diversity and abundances. The variability of abundances of each of the identified species in each of the experimental microcosms was explored using factorial analyses. A factorial correspondence analysis (FCA) was done first to quantify the contribution of each population to the observed variability in each microcosm. It emphasizes differences in abundances, but without discriminating sustained presence from ephemeral peaks of massive arrivals. In order to make this differentiation and give more weight to species having a sustained presence, a multiple correspondence analysis (MCA) was also done on a presence-absence table (abundances were replaced by 1 when strictly positive and by 0 otherwise). Because of the qualitative nature of the presence-absence coding, a complete disjunctive table (Burt Table) was computed. Percentages of the variance contribution of each axis were calculated, clouds of corresponding taxa and microcosms were plotted, and their relative and absolute variance contributions were calculated.

\section{Model design}

The model, based on fundamental concepts of population and community dynamics, was built to test ecological hypotheses about community assembly. The model was coded using SciLab (Scilab Enterprises, 2012, Version 5.5.2, available from: http://www.scilab.org) and simulates the generic early colonization process of individuals by several species in microcosms containing a single organic substrate used as the primary food source by primary consumers. This model was 
Table 1. Parameters $\left(a_{k}, r_{k}, m_{k}, g_{z, k}, e_{k}\right.$ and $\left.g_{y, k}\right)$ used in the colonization model (equation 1, Figure 2) representing the dynamics of the 5 interactive taxa identified in the study : Cspp, Capitella spp.; Gm, Gammaropsis maculata; Ep, Erichthonius punctatus; Np, Nereiphylla paretti; Hm, Harmothoe mariannae. $k, y$ and $z$ indicate the species. Mortality rates are determined from values found in the literature for similar ecosystems (see references below) and other values are based on order of magnitude. Despite the presence of 5 different identified taxa, the model can simplify to a 2 prey-1 predator system, by grouping 2 pairs: Gammaropsis maculata and Erichthonius punctatus, and Nereiphylla paretti and Harmothoe mariannae.

\begin{tabular}{|c|c|c|c|c|c|c|}
\hline Parameters & Units & $C \operatorname{spp}(k)$ & $G m(k)$ & $E p(k)$ & $N p(k)$ & $H m(k)$ \\
\hline \multicolumn{7}{|l|}{ Demographic rates } \\
\hline Arrival rate $\left(a_{k}\right)$ & ind.day ${ }^{-1}$ & 3 & 0.3 & 0.3 & 0.2 & 0.2 \\
\hline Reproduction rate $\left(r_{k}\right)$ & day-1 & 0.05 & 0.025 & 0.025 & 0 & 0 \\
\hline Mortality rate $\left(m_{k}\right)$ & day $^{-1}$ & $1 / 330^{a}$ & $1 / 180^{b}$ & $1 / 180^{b}$ & $1 / 540^{a}$ & $1 / 540^{\mathrm{a}}$ \\
\hline Exit rate $\left(e_{k}\right)$ & day $^{-1}$ & 0 & 0.01 & 0.01 & 0.02 & 0.02 \\
\hline \multicolumn{7}{|l|}{ Interaction matrices } \\
\hline \multirow[t]{6}{*}{ Predation rate $\left(g_{z, k}\right)$} & ind $^{-1}$. day $^{-1}$ & & & & & \\
\hline & $C \operatorname{spp}(z)$ & 0 & 0 & 0 & 0 & 0 \\
\hline & $G m(z)$ & 0 & 0 & 0 & 0 & 0 \\
\hline & $E p(z)$ & 0 & 0 & 0 & 0 & 0 \\
\hline & $\operatorname{Pm}(z)$ & 0.0035 & 0 & 0 & 0 & 0 \\
\hline & $H m(z)$ & 0.0035 & 0 & 0 & 0 & 0 \\
\hline \multirow[t]{6}{*}{ Competition weight $(\gamma)$} & unitless & & & & & \\
\hline & $C \operatorname{spp}(y)$ & 1 & 1 & 1 & 0 & 0 \\
\hline & $G m(y)$ & 1 & 1 & 1 & 0 & 0 \\
\hline & $E p(y)$ & 1 & 1 & 1 & 0 & 0 \\
\hline & $\operatorname{Pm}(y)$ & 0 & 0 & 0 & 1 & 1 \\
\hline & $H m(y)$ & 0 & 0 & 0 & 1 & 1 \\
\hline
\end{tabular}

a Giangrande 1997, b Bellan-Santini et al. 1998.

designed such that it can be adapted to: the conditions of the experiments, the functional traits of the species involved, and the range of interactions that individuals can develop. Five basic properties were defined:

(1) initial conditions are null (i.e., at time zero, microcosms contain no organisms) and organisms immigrate from a regional pool of species;

(2) local population dynamics are governed by specific reproduction and mortality processes and by a specific rate of emigration depending on the motility of the species;

(3) two types of biotic, interacting processes were considered - competition for food resources and predation and these are determined by the functional trait of the species;

(4) the primary source of food is non-limiting, hence competition processes between detritivores are only indirect; and

(5) the small population abundances imply that individual variability may prevail over the behavior of populations.

The resulting stochastic model simulates the size $N$ (in number of individuals) of each population (species $k$ ) in a set of microcosms (cages $i$ ). The general formulation is:

$N_{k, i}(t+\tau)=N_{k, i}(t)+\left[a_{k} \tau+N_{k, i}(t)\left(r_{k} \tau-m_{k} \tau-e_{k} \tau\right.\right.$

$\left.\left.\left(1-\frac{N_{k, i}(t)}{\sum_{y} \gamma_{y, k} N_{y, i}(t)}\right)-\sum_{z} g_{z, k} \tau N_{z, i}(t)\right)\right]$ where $\tau$ is a random variable, representing the time between two asynchronous events in the population dynamics. This variable accounts for the demographic stochasticity. $a_{k}$ is the arrival rate (ind.time- ${ }^{-1}$ ) of individual of species $k, r_{k}$ and $m_{k}$ (both in terms of time-1) respectively the reproduction and natural mortality rates, $\mathrm{e}_{\mathrm{k}}$ the maximum departure rate (time1), and $g_{z, k}$, the predation rate of species $z$ on species $k$ (ind ${ }^{-1}$. time $\left.^{-1}\right)$. The competition was designed as a function that modulated the departure rate $\left(e_{k}\right)$, and was indexed on the ratio of abundances of one species on the abundances of all species using the same resource in the same way. When a species is the only one to consume a resource, the competition function equals 0 . When a species compete with a large number of abundant populations for the consumption of the same resource, then the competition function converges to $1 . g_{y, k}$ (dimensionless) is a weighting factor calculated as the number of resources (primary or secondary) that species $k$ shares with species $y$, divided by the total number of resources that the species $k$ is exploiting (with the constraint that $g_{y, k}=1$, when $y=k)$.

The parameterization of the model (Table 1) depends on the traits of the species present and related habitat factors. The arrival rate depends on the average densities in the pool of species as well as on the average spatial distance between the potential source and the experimental device position. The maximum departure rate depends on the motility of the individuals. The reproduction rate depends on the average female fecundity, the proportion of reproductive females in the microcosms, the retention factor of juveniles and brooding duration. The mortality rate $\left(\right.$ time $\left.^{-1}\right)$ is the inverse of the specific 
life expectancy (Bellan-Santini et al. 1982, 1989, Giangrande 1997). Finally, grazing and predation rates depend on the average specific ingestion rate of individuals, the weight ratio between predator and their preys, and the predator preferential feeding for their respective preys.

\section{Results}

\section{Verification of experimental assumptions}

All microcosms still contained unconsumed vine leaves even after 3 months. The presence of large amounts of leaves in the experimental microcosms during the entire experiment is consistent with our assumption that the quantity of food resource was not a limiting factor for the colonization.

Results of taxonomic richness and total abundances are presented Figure 1. All microcosms were colonized, and a
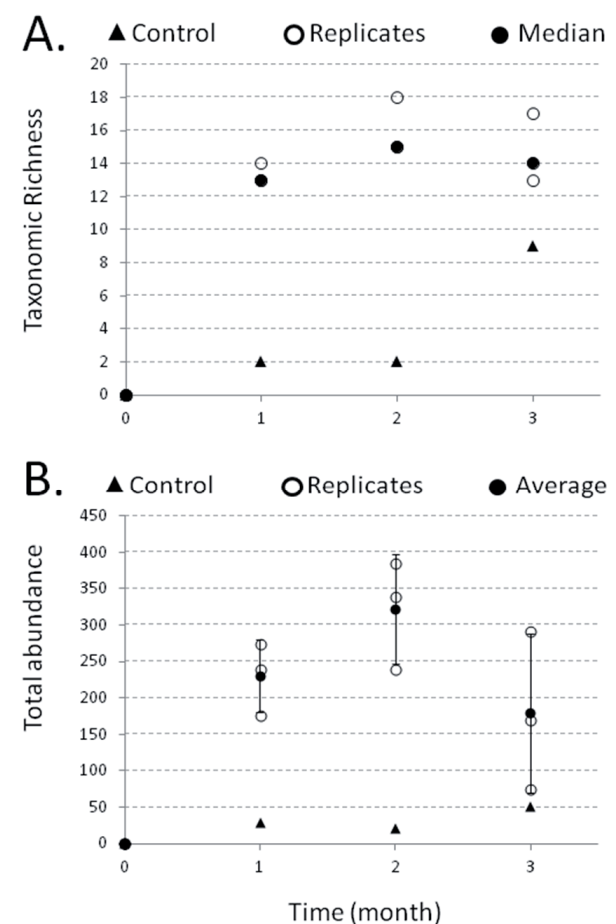

Figure 1. Basic biodiversity information on the observed community. A) Total taxonomic richness for the three replicates, the median of the three replicates and the control microcosms for each sampling months. A total of 51 taxa were identified, and a maximum of 18 taxa were observed at the same time in one replicates. After 1 month, the median of replicates appeared to be stable, which was not the case in the control microcosm. B) Total abundance for the three replicates, average of the three replicates and the control microcosms for each sampling month. The maximum was reached in replicates at month 2 (386 individuals counted all taxa confounded) and decreased at month 3 . In average, $86 \%$ of the total abundance was due to 5 taxa only, Capitella spp., Gammaropsis maculata, Erichthonius punctatus, Nereiphylla paretti and Harmothoe mariannae. Capitella spp. disappeared at month 3 in the 3 replicates but remained in the control microcosm. total of 51 taxa were identified (47 at the species level and 4 at the genus level). In the replicates, the medians of the taxonomic richness were 13 for M1, 15 for M2 and 14 for M3 (Figure 1A). In the "control" microcosms, some individuals were found too; the taxonomic richness was equal to 2, 2, and 9 for months 1, 2 and 3 respectively, and abundances remained low (maximum of 26 individuals for the most represented taxon Capitella spp.). In general, the microcosms contained low population abundances (Figure 1B) . The maximum abundance was recorded for the taxon Capitella spp. at 316 individuals for month 2 , and the average abundance per taxa was equal to 17 individuals. Maximums of abundances and taxonomic richness were reached at month 2 and variability increased from the beginning to month 3 .

\section{Observed population variability and functional traits of the species}

The FCA (Figure 2A) indicated temporal changes in the assemblage of the 51 taxa. The first axis explained about $58 \%$ of the total variability. Three taxa, (one polychaete, Capitella spp. and two amphipods, Gammaropsis maculata and Erichthonius punctatus) explained $56 \%$ of this variability. The second axis, representing about $16 \%$ of the total variability, showed that differences between microcosms increased with sampling times; maximum differences at the third month (M3) were mainly due to two species, G. maculata and E. punctatus.

The MCA (not shown here) provided a slightly different classification. The two first axes represented respectively $39.2 \%$ and $12.1 \%$ of the total variability. The first axis opposed the most common species (found in large abundances and consistently at each sampling time) to the rare and occasional ones (found in very low abundances and/or once or a few times in the samples). As for the FCA, the second axis accounted for the increasing temporal variability between microcosms. The overall variability on the first 2 axes was due to four species, G. maculata, E. punctatus, and two polychaetes Nereiphylla paretti and Harmothoe mariannae, explaining $23 \%$ of the total variability.

Combining the overall contributions of each species for the first two axes of the two analyses (FCA and MCA, Figure 2B), and considering that the contribution was not significant if lower than 5\%, five taxa, Capitella spp., G. maculata, E. punctatus, $N$. paretti and H. mariannae, were found to have a major impact on the dynamics of the colonization process observed in this experiment. They represented $80 \%$ of the total abundances. Three of these are primary consumers (Capitella spp., G. maculata and E. punctatus) and two are predators ( $N$. paretti and H. mariannae, Fauchald and Jumars 1979).

\section{Dynamics of the populations}

The dynamics were inferred from series of observations performed on 3 independent experimental units of 3 microcosm replicates sampled at 1-month intervals. For this, it was 
hypothesized that the same process has generated the observed community composition in each of the microcosms. Three distinct trends were identified; one for Capitella spp., a second for G. maculata and E. punctatus and a third one for N. paretti and H. mariannae (data shown in Figure 3). Capitella spp. showed a sharp initial increase reaching a maximum of 316 individuals (at month 2) followed by a sharp decrease down to zero at the end of the experimentation. For the two first months, both the average and the variability between microcosms increased. The abundances of the amphipods ( $G$. maculata and E. punctatus) increased gradually, reaching a maximum of 154 and 91 individuals per microcosm respec-
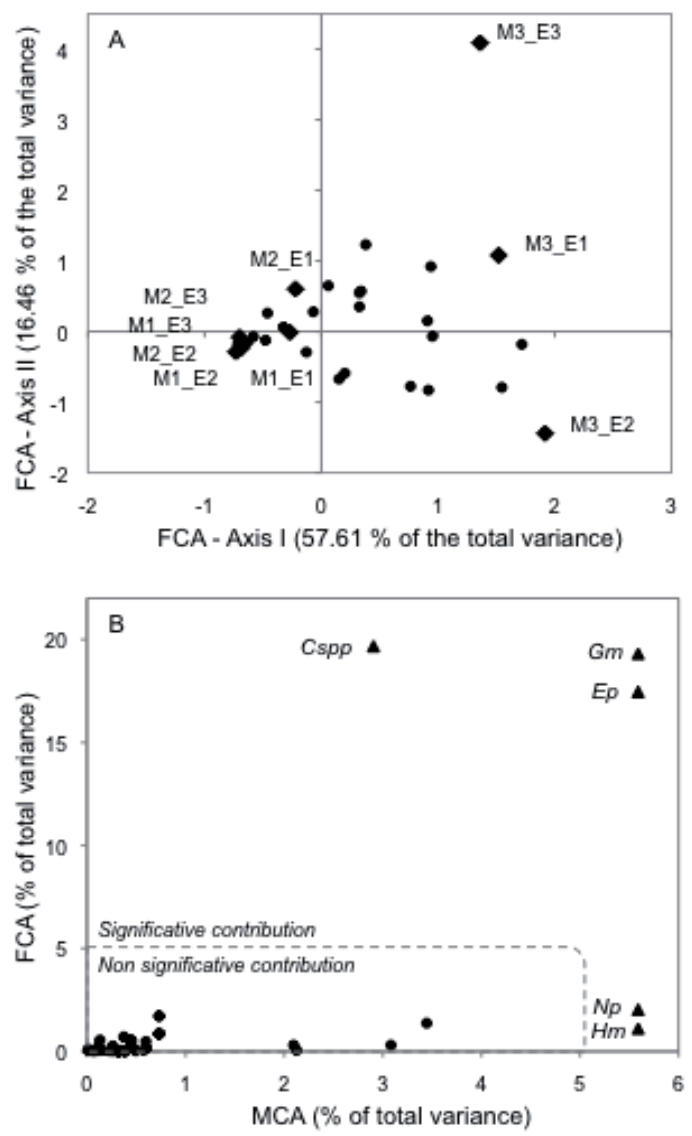

Figure 2. A) Projection plan of the two first axes of the Factorial Correspondence Analysis (FCA) performed on the contingency table of the taxa abundances in experimental microcosms. Taxa are depicted by dots and microcosms by diamonds. Axis I, representing $57.61 \%$ of the overall variance, accounted for temporal changes in taxa composition, separating M1 and M2 from M3. Axis II, representing $16.46 \%$ of the overall variance, accounted for the variability between microcosms, mainly separating $\mathrm{C} 1$, $\mathrm{C} 2$ and $\mathrm{C} 3$ of M3. B) taxa contributions to the total variances of the FCA performed on the abundances matrix and the Multiple Correspondence Analysis (MCA) performed on the presence-absence matrix. The 5 species that contributed significantly (i.e., for more than $5 \%$ of the total variance) to the observed variability, at least in one of the two analyses, were Cspp = Capitella spp.; Gm = Gammaropsis maculata $; \mathrm{Ep}=$ Erichthonius punctatus; $N p=$ Nereiphylla paretti; $\mathrm{Hm}=$ Harmothoe mariannae. tively, at month 3. N. paretti and H. mariannae had the lowest abundances, reaching (respectively) a maximum of 28 and 12 individuals per microcosm at month 2 . Their abundances remained steady or decreased slightly at month 3 , together with a decrease of the inter-microcosm variability.

\section{Simulating the dynamics of the early colonization}

Figure 3 superimposes simulations on the experimental observations for each of the five taxa retained for the model. Simulations are represented by the averaged trajectories (based on 300 simulations, representing 100 probable community dynamics in 3 experimental replicates) and their standard errors as a measure of their uncertainty. The initial dynamics were characterized by the monotonous temporal increase of the 5 structuring species populations. This was due to two processes: (i) the immigration of new individuals (adults or juveniles) from external populations, and (ii) the local reproduction of adults.

The first series of simulations were carried out in conditions of no interactions (Figure 3, left column). Predation rates were set to zero $\left(g_{z, k}=0\right.$ in eq. 1) and competition between predator species was removed $\left(g_{y, k}=0\right)$ but their exit rates were set to their maximum values $\left(0.02\right.$ day $\left.^{-1}\right)$ since no food sources were considered. These simulations without inter-specific interactions showed monotonous trends, with two different patterns between potential preys (exponential increases) and predators (asymptotically limited increase), and a complete lack of adequacy between observed (points and simulated population dynamics of the Capitella spp).

Secondly, simulations including prey-predator and competitive interactions between organisms of different populations (Figure 3, right column) were done. These simulations generated completely different outcomes, and were much closer to the observations. In particular, the quantitative implementation of predation pressure reduced significantly the abundances of Capitella spp. at the end of the 3-month simulation. Therefore, in these conditions, the main characteristics are well-represented, that is: (1) the massive arrival of Capitella spp., which dominated the assemblage composition up to month 2 ; (2) a switch of dominance between primary consumers at month 3; and (3) a slight increase of predator abundances at the end of the colonization phase. Moreover, as seen in the experiments, the inter-microcosm variability increased with time, except for the dynamics of the Capitella spp. which decreased when the abundances collapsed at the end of month 3. Despite the large number of possible trajectories (Drake 1999), the simulation approach was in good agreement with experiments (Figure 3, column B). This emphasized the capacity of the experimental design to reduce the multiplicity of assemblage outcomes in the modelling. However, no optimization procedures can be done since observations are made on independent units (each being a different realization of a stochastic process), which is the contrary of the simulations. 
Without Predation Interactions

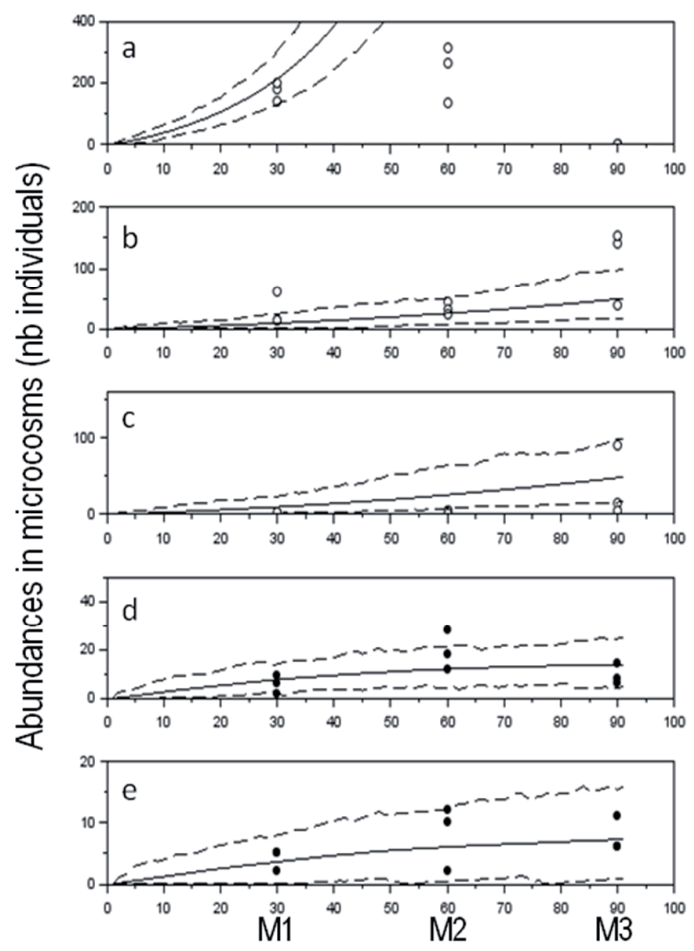

With Predation Interactions
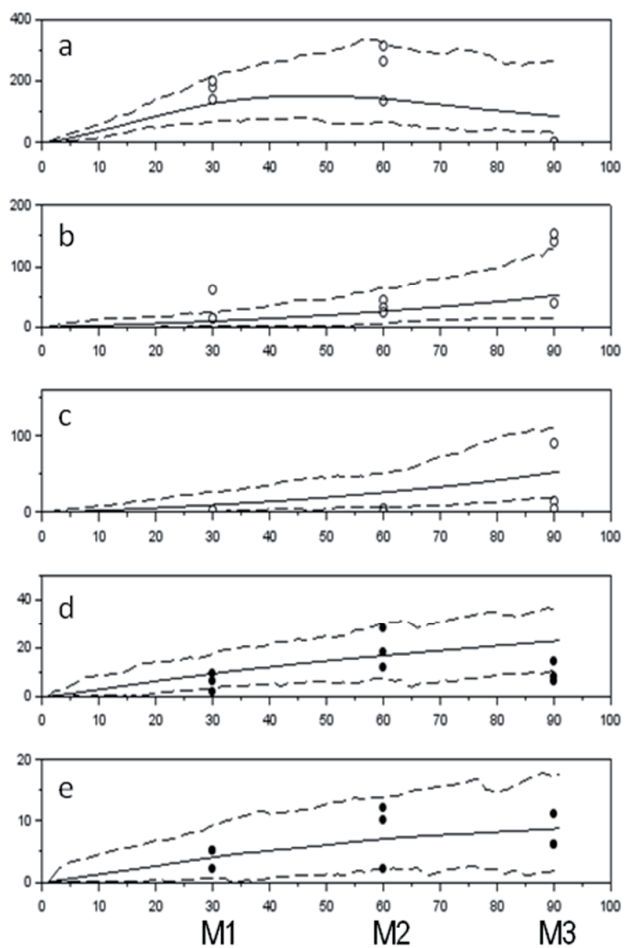

Figure 3. Confrontation of the observations (empty circles for primary consumers and filled circles for predators) and results of 100 simulations of the stochastic model (average in solid lines, and boundaries of all simulations in dashed line). On the left are simulations performed with no predation interactions. On the right are simulations performed with predation of the two predators, Nereiphylla paretti and Harmothoe mariannae on the capitellids. When taking into account predations, simulations recovered most of the observations. This was not the case when predation interactions were considered as null. However, simulations suggested that observations are very few compared to the very large range of possible solutions: a) Capitella spp.; b) Gammaropsis maculata; c) Erichthonius punctatus; d) Nereiphylla paretti; e) Harmothoe mariannae.

\section{Discussion}

The experiment was based on using terrestrial debris, which is one of the main sources of organic matter in aquatic environments, even if it depends on recurrent inputs (Dickinson and Pugh 1974, Moore et al. 2004, Charles et al. 2014). In the microcosms, enough resource was provided such that it would not be a limiting factor during these shortterm experiments. Capitella spp. arrived early and massively in microcosms. Commonly, capitellids are described as deposit-feeders, relying on the detritic organic matter contained in the sediment (Fauchald and Jumars 1979). All specimens found in the microcosms were embedded into the tissues of the leaves. They were considered to feed on mesophyll tissue because they were dragging a mucus thread containing faecal pellets between the cuticles of the leaf. And, unlike continental aquatic systems (Cummins 1974), shredding does not seem to be a prerequisite for the use of leaves by communities of marine invertebrates.

The microcosms used as a "control" provided crucial information, in particular about the persistence of the main primary consumers Capitella spp., whereas their populations from experimental microcosms collapsed at month 3 (experimental points in Figure 3). The main difference was the absence of predators ( $N$. paretti and $H$. mariannae) in these "control" microcosms because adults from the surrounding environment were prevented from entering by the mesh size used.

Each of the observations, as they were independent, represents a single isolated realization of the observed stochastic process. The observed variability in the experimental realizations could result both from internal (i.e., demographic) and external (i.e., environmental) factors. The observed assemblages showed that the 3 replicates sampled at each time step were not completely divergent in species composition, abundances or dominance hierarchy, whereas total variability increased with time. It thus appears that local processes (i.e., demographic) were more structuring than regional ones (i.e., arrival or departure). This result is not consistent with earlier theoretical developments which suggested that when population densities are low, demographic stochasticity can lead to unpredictability in the resulting community assemblage (May 1974, Henson et al. 2003). It may lead to the exclusion of some populations but also to the emergence of many species that are categorized as rare or occasional. In our study, the 5 dominant species were found in all microcosms, and only $26 \%$ of the total FCA variability accounted for the 46 rare and occasional taxa that were assumed to be neutral with respect to the whole community assembly. However, despite an important, time-consuming, effort dedicated to the taxonomic 
identification, the total number of 9 independent observations (3 replicates $\times 3$ months) was too small to draw statistically significant differences about the early colonization process. This is why the model of colonization focusing on the role of interactions in the early assemblage process was foreseen as useful to test if the dynamics of the observed community, restricted to only 5 interacting species, was susceptible to unpredictability or not.

The major difficulty when using experimental results in a colonization model is the parameterization of processes, which generally exceed what can be performed from existing information (Drake 1991). Table 1 summarizes the parameters used in the model. The arrival rates of individuals were assumed to be a function of the density and spatial distribution of their potential source populations. The preferential habitat of the amphipods, G. maculata and E. punctatus, are algae and sea grass meadows (Bellan-Santini et al. 1982, 1989), biotopes that occurred 200 meters from where the experimental units were installed. For polychaetes, their preferred habitat is soft sediment (Fauvel 1923, 1927) such as that in the vicinity of the installations. The highest arrival rate was attributed to Capitella spp. (Table 1) and arrival rates for all other species were an order of magnitude lower. Arrival rates of predators were assumed to be the lowest, since their densities are usually lower in the environment, and also at the beginning of the experiment, there were no prey in the microcosms.

Ovigerous females in the microcosms indicated the occurrence of local reproduction for Capitella spp., G. maculata and E. punctatus during the experiment. Females from these taxonomic groups have brooding behavior with retention of embryos and juveniles. The highest reproduction rate was attributed to Capitella spp. because females incubate hundreds of embryos, while amphipod females incubate 10 times less. The reproduction rates of $N$. paretti and $H$. mariannae were set to zero; $N$. paretti encapsulates embryos in a gelatinous mass and species of Harmothoe genus are free spawners but in both cases, reproduction ends by the release of planktotrophic larvae (Wilson 1991).

Finally, parameters for exit rates (Table 1) of the primary consumers were considered to be null since the primary food resource (vine leaves) was not limited. For predators, maximum exit rates were set at 0.02 day $^{-1}$.

The trophic behaviors of the five taxa conditioned the structure of the food web that was defined for the model in a minimum way. Predators, $N$. paretti and H. mariannae, were able to feed on the three primary consumers, which were smaller in size. Preferences were given to Capitella spp., which is the less motile prey. Considering orders of magnitude $\left(10^{-3}\right.$ ind $^{-1}$.day $\left.{ }^{-1}\right)$, it was not possible to differentiate a specific predation rate on Capitellidae by both predator species.

Given this information on species traits, the model parameterization was kept to a minimum, by grouping certain species under the same parameters. As such, the two predator species $-N$. paretti and $H$. mariannae - are described in the model by the same set of demographic parameters. These predators were then considered functionally as one "population" since they have the same effect on the dynamics of their prey (Arditi and Michalski 1995). This property of "invariance by species identification" was also applied to the amphipods E. punctatus and G. maculata reducing even further the complexity of the model.

Recent work has emphasized the importance of transient dynamics rather than long-term behavior in ecological systems (Hasting 2004). Quantifying transient phenomena is thus becoming a necessary part of community assembly studies, especially those involved in the early colonization stages. By combining in situ experiments and modelling, we found that predation may have a major influence on the community composition in these early stages. Interestingly, the experimental time frame of the colonization phase was sufficiently long to show that predation can lead to the disappearance of a prey population, as suggested by Fox and McGrady-Steed (2002). Despite the high arrival rate of Capitella spp. individuals, the assembly did not conform to a mass effect dynamic (Leibold et al. 2004). The collapse of the capitellids could not result from departure or stress-induced mortality, but was more likely from the presence of their predators. Indeed, the continued presence of capitellids in the control microcosms allowed us to discard hypotheses of "natural" ecological succession prevalent in earlier literature (e.g., Odum et al. 1971). These observations together with results of model outputs suggested that predation has a strong role in structuring the community assembly from the earliest phase of colonization. It suggests that theoretical paradigms (Leibold et al. 2004) should consider trophic interactions with the same dynamic importance as the competition or dispersal processes in a community that colonizes a new habitat (Fahimipour and Hein 2014). It supports an early phase of assembly in which predators maintain a higher diversity by regulating high densities of competing organisms (Paine 1966, Leibold 1996, Chase et al. 2009). The contrary can be argued as well, since predation only triggers a change of dominance and not a leveling of dominant species in microcosms. To test this explicitly, our model should take into account the overall community dynamics, including the 46 species for which ad hoc parameters have to be determined, and concomitantly, many other experimental replicates should be sampled.

To summarize, our preliminary results suggest that trophic processes that are usually disregarded in early community assembly should be accounted for. In previous studies carried out in environments which are limited in resources and with controlled densities of introduced predators, Fox and McGrady-Steed (2002), Kraus and Vonesh (2010) and Hein and Gillooly (2011) have suggested that predation may control community structure during the colonization phase. Our study supports this interpretation while avoiding the experimental constraints of fixing the timing, the community composition and the rates of predator arrivals in the experiment. However, interpretations are far from a complete understanding of the early process of colonization. This would first require quantifying the reciprocal relationships between the assembling community and resource(s) dynamics (in terms of quality and structure), which is a series of ecogeochemi- 
cal feedbacks for which few conceptual frameworks exist (Charles et al. 2014). These first results presented here then provide a concrete starting point for progressing toward the fundamental understanding of the early colonization process.

Acknowledgements. The authors would like to thank N. Loeuille for his valuable comments on the design of the study and on the content of this manuscript. This paper was performed in the framework of the international laboratory, CNRS-INEE/UQAR-ISMER "BeBEST" (Benthic Biodiversity Ecology Sciences and Technologies), which is a Franco-Québecois research initiative about coastal ecology.

\section{References}

Arditi, R. and Michalski, J. 1995. Non linear food web models and their response to increased basal productivity, in: Polis, G.A. and Winemiller, K.O. (eds), Food Webs: Integration of Patterns and Dynamics. Chapman and Hall, London, pp. 122-133.

Arroyo, N.L., Aarnio, K. and Bonsdorff, E. 2006. Drifting algae as a means of re-colonizing defaunated sediments in the Baltic Sea. A short-term microcosm study. Hydrobiologia 554: 83-95.

Bellan-Santini, D., Karaman, G., Krapp-Schickel, G., Ledoyer, M., Myers, A., Ruffo, S. and Schiecke, U. 1982. The Amphipoda of the Mediterranean. Part 1: Gammaridae (Acanthonotozomatidae to Gammaridae). Mémoires de l'Institut océanographique, Monaco, 13. Institut Océanographique, Monaco.

Bellan-Santini, D., Diviacco, G., Krapp-Schickel, G. and Ruffo, S. 1989. The Amphipoda of the Mediterranean. Part 2: Gammaridea (Haustoriidae to Lysianassidae). Mémoires de l'Institut océanographique, Monaco, 13. Institut Océanographique, Monaco.

Bellan-Santini, D., Karaman, G., Ledoyer, M., Myers, A., Ruffo, S. and Vader, W. 1998. The Amphipoda of the Mediterranean. Part 4: Localities and Map, Addenda to Parts 1-3, Key to Families, Ecology, Faunistics and Zoogeography, Bibliography, Index. Mémoires de l'Institut océanographique, Monaco, 13. Institut Océanographique, Monaco.

Charles, F., Coston-Guarini, J., Lantoine, F., Guarini, J.M. and Yücel, M. 2014. Ecogeochemical fate of coarse organic particles in sediments of the Rhône River prodelta. Est. Coast. Shelf. Sci. 141: 97-103.

Chase, J.M., Biro, E.G., Ryberg, W.A. and Smith, K.G. 2009 Predators temper the relative importance of stochastic processes in the assembly of prey metacommunities. Ecol. Lett. 12: 12101218.

Chesson, P. 2000. Mechanisms of maintenance of species diversity. Annu. Rev. Ecol. Syst. 31: 343-366.

Cummins, K. W. 1974. The importance of different energy sources in freshwater ecosystems. Pages 50-54 in Reichle, D.E., J.F. Franklin and D.W. Goodall (eds.), Productivity of World Ecosystems. Proc. Symp. IBP General Assembly, Nat. Acad. Sci. Washington, D.C.

Dickinson, C.H. and Pugh, G.J.H. 1974. Biology of Plant Litter Decomposition. Academic Press, London and New York.

Drake, J.A. 1991. Community-assembly mechanics and the structure of an experimental species ensemble. Am. Nat. 137: 1-26.

Drake, J.A., Zimmerman, C.R., Purucker, T. and Rojo, C. 1999. On nature of the assembly trajectory. In: Weiher, E. and Keddy, P.A. (eds), Ecological Assembly Rules: Perspectives, Advances, Retreats. Cambridge University Press, pp. 233-250.
Eggleston, D.B., Elis, W.E., Etherington, L.L., Dahlgren, C.P. and Posey, M.H. 1999. Organism responses to habitat fragmentation and diversity: habitat colonization by estuarine macrofauna. $J$. Exp. Mar. Biol. Ecol. 236: 107-132.

Fahimipour, A.K. and Hein, A.M. 2014. The dynamics of assembling food webs. Ecol. Lett. 17: 606-613.

Fauchald, K. and Jumars, P.A. 1979. The diet of worms: a study of polychaete feeding guilds. Oceanogr. Mar. Biol. Ann. Rev. 17: 193-284.

Fauvel, P., 1923. Faune de France 5. Polychètes errantes. Fédération Française des Sociétés de Sciences Naturelles, Paris.

Fauvel, P. 1927. Faune de France 16. Polychètes sédentaires Fédération Française des Sociétés de Sciences Naturelles, Paris.

Fox, J.W. and McGrady-Steed, J. 2002. Stability and complexity in microcosm communities. J. Anim. Ecol. 71: 749-756.

Giangrande, A. 1997. Polychaete reproductive patterns, life cycles and life histories: an overview. Oceanogr. Mar. Biol. 35: 323 386.

Hastings, A. 2004. Transients: the key to long-term ecological understanding. Trends Ecol. Evol. 19: 39-45.

Hein, A.M. and Gillooly, J.F. 2011. Predators, prey, and transient states in the assembly of spatially structured communities. Ecology 92: 549-555.

Henson, S.M., King, A.A., Costantino, R.F., Cushing, J.M., Dennis, B. and Desharnais, RA. 2003. Explaining and predicting patterns in stochastic population systems. Proc. R. Soc. Lond. B. 270: $1549-1553$.

Holyoak, M., Leibold, M.A. and Holt, R.D. 2005. Metacommunities. Spatial Dynamics and Ecological Communities. University of Chicago Press, Chicago.

Kraus, J.M. and Vonesh, J.R. 2010. Feedbacks between community assembly and habitat selection shape variation in local colonization. J. Anim. Ecol. 79: 795-802.

Lee, S.Y. 1999. The effect of mangrove leaf litter enrichment on macrobenthic colonization of defaunated sandy substrates. Est. Coast. Shelf. Sci. 49: 703-712.

Leibold, M.A. 1996. A graphical model of keystone predators in food webs: Trophic regulation of abundance, incidence, and diversity patterns in communities. Am. Nat. 147: 784-812.

Leibold, M.A., Holyoak, M., Mouquet, N., Amarasekare, P., Chase, J.M., Hoopes, M.F. et al. 2004. The metacommunity concept: a framework for multi-scale community ecology. Ecol. Lett. 7: $601-613$.

Lu, L. and Wu, R.S.S. 2000. An experimental study on recolonization and succession of marine macrobenthos in defaunated sediment. Mar. Biol. 136: 291-302.

Maria, T.F., Esteves, A.M., Vanaverbeke, J. and Vanreusel, A. 2011 The effect of the dominant polychaete Scolelepis squamata on nematode colonisation in sandy beach sediments: An experimental approach. Est. Coast. Shelf Sci. 94: 272-280.

May, R.M. 1974. Biological populations with nonoverlapping generations: stable points, stable cycles, and chaos. Science 186: 645-647.

McCreary Waters, N., Auro, M.E., Hagen, T. and Lavalley Dumont, K. 2005. How colonization time influences macroinvertebrate community measures on artificial substrates. J. Freshwater Ecol. 20: 9-16.

Moritz, C., Loeuille, N., Guarini, J.M. and Guizien, K. 2009. Quantifying the dynamics of marine invertebrate metacommunities: What processes can maintain high diversity with low densities in the Mediterranean Sea? Ecol. Model. 220: 3021-3032. 
Moritz, C., Meynard, C.N., Devictor, V., Guizien, K., Labrune, C., Guarini, J.M. and Mouquet, N. 2013. Disentangling the role of connectivity, environmental filtering, and spatial structure on metacommunity dynamics. Oikos 122: 1401-1410.

Moore, J.C., Berlow, E.L., Coleman, D.C., de Ruiter, P.C., Dong, Q., Hastings, A., Johnson, N.C., McCann, K.S., Melville, K., Morin, P.J., Nadelhoffer, K., Rosemond, A.D., Post, D.M., Sabo, J.L., Scow, K.M., Vanni, M.J. and Wall, D.H. 2004. Detritus, trophic dynamics and biodiversity. Ecol. Lett. 7: 584-600.

Naser, H.A. 2011. Effects of reclamation on macrobenthic assemblages in the coastline of the Arabian Gulf: A microcosm experimental approach. Mar. Pollut. Bull. 62: 520-524.

Odum, E.P., Odum, H.T. and Andrews, J. 1971. Fundamentals of Ecology (Vol. 3). Saunders, Philadelphia, PA.

Paine, R.T. 1966. Food web complexity and species diversity. Am. Nat. 100: 65-75.

Palmer, M.A., Allan, J.D., and Butman, C.A. 1996. Dispersal as a regional process affecting the local dynamics of marine and stream benthic invertebrates. Trends Ecol. Evol. 11: 322-326.

Petraitis, P.S. and Dudgeon, S.R. 1999. Experimental evidence for the origin of alternative communities on rocky intertidal shores. Oikos 84: 239-245.

Scrimgeour, G.J., Davidson, R.J. and Davidson, J.M. 1988. Recovery of benthic macroinvertebrate and epilithic communities follow- ing a large flood, in an unstable, Braided, New Zealand River. New Zeal. J. Mar. Fresh. 22: 337-344.

Tilman, D. 1994. Competition and biodiversity in spatially structured habitats. Ecology 75: 2-16.

Tilman, D. 2004. Niche tradeoffs, neutrality, and community structure: a stochastic theory of resource competition, invasion, and community assembly. Proc. Natl. Acad. Sci. USA, 101: 1085410861.

Weiher, E., Freund, D., Bunton, T., Stefanski A., Lee, T. and Bentivenga, S. 2011. Advances, challenges and a developing synthesis of ecological community assembly theory. Phil. Trans. R. Soc. B. 366: 2403-2413.

Wilson, H.W. 1991. Sexual reproductive modes in polychaetes: classification and diversity. Bull. Mar. Sci. 48: 500-516.

Received December 26, 2015

Revised May 21, 2016

Accepted May 30, 2016

\section{Appendix}

List of identified taxa. The file may be downloaded from www. akademiai.com. 